\title{
THE BIOLOGICAL ACTIVITIES OF TROPONOIDS AND THEIR USE IN AGRICULTURE
}

\author{
A REVIEW \\ Marian SANIEWSKI ${ }^{1}$, Marcin HORBOWICZ ${ }^{2 *}$, Sirichai KANLAYANARAT ${ }^{3}$ \\ ${ }^{1}$ Research Institute of Horticulture, Konstytucji 3 Maja 1/3, 96-100 Skierniewice, Poland \\ ${ }^{2}$ Siedlce University of Natural Sciences and Humanities \\ Faculty of Natural Sciences, Department of Plant Physiology and Genetics \\ Prusa 12, 08-110 Siedlce, Poland \\ ${ }^{3}$ School of Bioresources and Technology, King Mongkut's University of Technology Thonburi \\ Thungkru, Bangkok 10140, Thailand
}

Received: May 19, 2014; Accepted: June 11, 2014

\begin{abstract}
Chemical compounds containing the tropone structure (2,4,6-cycloheptatrien-1-one), in their molecule, called troponoids, characterized by a seven-membered ring, are distributed in some plants, bacteria and fungi, although they are relatively rare. 3 -Thujaplicin (2-hydroxy-4-isopropyl-2,4,6-cycloheptatrien-1-one), also known as hinokitiol, is a natural compound found in several plants of the Cupressaceae family. Besides hinokitiol, related compounds were identified in Cupressaceae trees. It has been demonstrated that hinokitiol and its derivatives have various biological effects, such as antibacterial, antifungal, insecticidal, antimalarial, antitumor, anti-ischemic, iron chelating and the inhibitory activity against polyphenol oxidase activity. Activity similar to ß-thujaplicin has tropolone and its derivatives, which are not present nature. Due to the high scientific and practical interest, synthetic $\beta$-thujaplicin and other troponoids have been produced for many years. In this review, the major biological effects of troponoids, mostly $\beta$-thujaplicin and tropolone, on tyrosinase and polyphenol oxidase activity, ethylene production, antibacterial, antifungal and insecticidal activities, and biotransformation of $\beta$-thujaplicin by cultured plant cells are presented. Accumulation of ß-thujaplicin and related troponoids has been shown in cell cultures of Cupressus lusitanica and other species of Cupressaceae. The biosynthetic pathway of the troponoids in plants, bacteria and fungi has been also briefly described.
\end{abstract}

Key words: Cupressaceae, $\beta$-thujaplicin, tropolone, polyphenol oxidase, biosynthesis antibacterial, antifungal, insecticidal activity

\section{INTRODUCTION}

Tropones and tropolones raise increasing interest in the past few years due to their potential for use in medicine or commerce; approximately 200 such compounds occur in nature (Bentley 2008). Biological tissues containing the tropolone structure characterized by a seven-membered ring and an alphahydroxyl ketone are distributed in plants, bacteria and fungi, although they are relatively rare (Cox
\& Al-Fahad 2013). Two of the most known troponoids, ß-thujaplicin and colchicine, were found in plant tissues. Colchicine was first isolated in 1820 from autumn crocus (meadow saffron, Colchicum autumnale), although its structure was determined only in middle of $20^{\text {th }}$ century (King et al. 1952).

ß-Thujaplicin (2-hydroxy-4-isopropyl-2,4,6cycloheptatrien-1-one), also known as hinokitiol (Fig. 1), is a natural substance found in several plants of the Cupressaceae family. The structure of 
ß-thujaplicin is based on a unique conjugated sevenmembered ring called a tropolone ring. It has been demonstrated that hinokitiol have a variety of biological effects, such as antibacterial, antifungal, antitumor, anti-ischemic, iron chelating, insecticidal, antimalarial and inhibitory activity against polyphenol oxidase (Zhao 2007; Bentley 2008; Saniewski et al. 2007). Some other hinokitiol-related compounds were identified in Cupressaceae trees with similar or lesser activities to ß-thujaplicin. Details on occurrence of $\beta$-thujaplicin and related compounds including $\alpha$-thujaplicin, $\gamma$-thujaplicin, $\beta$-thujaplicin, $\beta$-dolabrin, nootkatin and others (Fig. 1) in several Cupressaceae trees were reviewed by Haluk and Roussel (2000), Chedgy et al. (2007) and Zhao (2007). Distribution of troponoids (ß-thujaplicin and related compounds) was documented in the heartwood of the following tree species: Chamaecyparis obtusa, Ch. lawsoniana, Ch. taiwanensis, Ch. thyoides, Cupressus lusitanica, C. arizonica, C. macnabiana, C. macrocarpa, C. torulosa, Juniperus chinensis, J. cedrus, J. communis, J. californica, J. occidentalis, J. oxycedrus, J. sabina, Calocedrus decurrens, C. formosana, Platycladus orientalis, Thuja occidentalis, T. plicata, T. standishii, Thujopsis dolabrata, and Tetraclinis articulata.

Biosynthesis of B-thujaplicin has been shown in cell cultures of $C$. lusitanica (Inada et al. 1993; Itose \& Sakai 1997; Yamaguchi et al. 1999; Yamada et al. 2003), C. formosana (Ono et al. 1998), T. plicata (Haluk \& Roussel-Bousta 2003) and T. dolabrata var. hondai (Fuji et al. 1995).

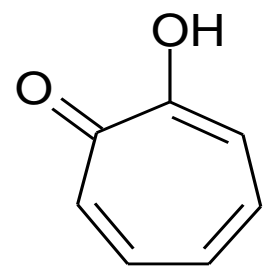

tropolone<smiles>CC(C)c1ccccc(=O)c1O</smiles>

$\alpha$-thujaplicin<smiles>CC(C)=CCc1ccc(=O)c(O)cc1C(C)C</smiles>

nootkatin

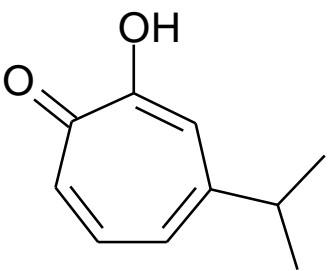

$\beta$-thujaplicin (hinokitiol)<smiles></smiles>

colchicine<smiles>CC(C)c1ccc(O)c(=O)cc1</smiles>

$\gamma$-thujaplicin<smiles>CC(C)c1ccc(O)c(=O)c(O)c1</smiles>

$\beta$-thujaplicinol

Fig. 1. Chemical structures of major troponoids 
Many factors affect the accumulation of B-thujaplicin in cell cultures of Cupressus lusitanica: elicitors (yeast extract, sodium alginate, chitin, methyl jasmonate), $\mathrm{Fe}^{2+}, \mathrm{Ca}^{2+}$, G-proteins, reactive oxygen species, $\mathrm{H}_{2} \mathrm{O}_{2}$, adenosine 3',5' cyclic AMP, peroxidase and others. It is believed that crosstalk between jasmonates and ethylene pathways plays a very important role in biosynthesis and accumulation of hinokitiol in cell suspension cultures of $C$. lusitanica (Zhao \& Sakai 2003a, b; Zhao et al. 2001, 2003, 2004, 2005, 2006, 2007).

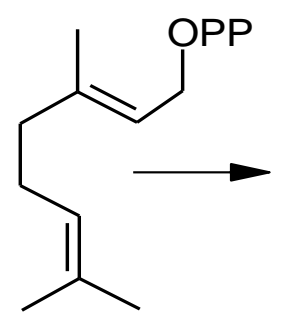

GDP

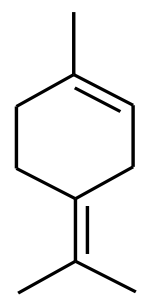

Terpinolene

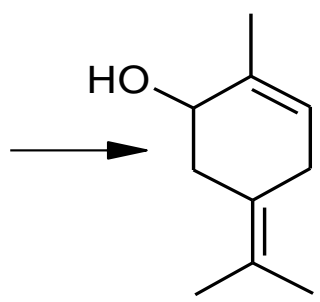

IME

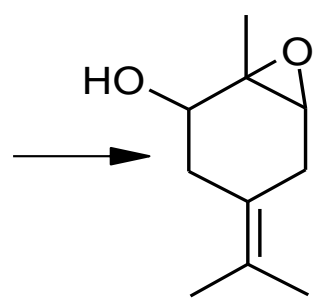

EMO

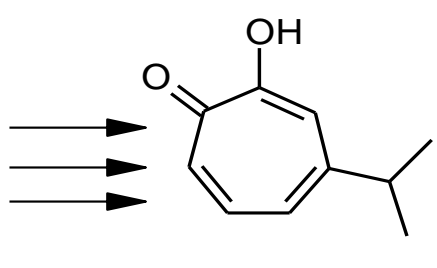

$\beta$-Thujaplicin (Hinokitiol)

Fig. 2. Simplified biosynthetic pathway of $\beta$-thujaplicin (hinokitiol) in Cupressus lusitanica cultured cells (Harada et al. 2012): GDP - geranyl diphosphate, IME - 5-isopropylidene-2-methylcyclohex-2-enol, and EMO: 1,6epoxy-4(8)-p-menthen-2-ol

\section{EFFECTS OF TROPONOIDS ON TYROSINASE AND POLYPHENOL OXIDASE ACTIVITY}

Enzymatic browning is one of the most studied processes in fruits, vegetables and other agricultural products. This process has an economic significance because it influences the storage, processing and quality of agricultural products. The browning is catalysed by the various polyphenol oxidases, such as phenoloxidase, phenolase, monophenol oxidase, diphenol oxidase and tyrosinase. Polyphenol oxidases are believed to play key physiological roles both in preventing insects and microorganisms from attacking plants and are part of the wound response of plants and plant products against insects, microorganisms and bruising. Polyphenol oxidase catalyses the production of quinones from phenolic compounds, and these quinones undergo reactions with amino acids, leading to the production of melanins. The melanins form barriers and have antimicrobial properties which prevent the spread of infection or bruising in plant tissues (Marshall et al. 2000; Kim \& Uyama 2005).
A number of tyrosinase inhibitors of both natural and synthetic sources that inhibit monophenolase and diphenolase activities have been identified. Among all these inhibitors assayed to date, tropolone is one of the most potent (Kim \& Uyama 2005). Tropolone inhibits both mono- and o-dihydroxyphenolase activity of mushroom tyrosinase when monohydroxyphenols (L-tyrosine) or o-hydroxyphenols (3,4-dihydroxyphenylanine - DOPA, dopamine, 4-methyl catechol) were used as the substrates (Kahn \& Andrawis 1985a).

Tropolone tested in the concentration range of 0.3 to $200 \mu \mathrm{M}$ proved that the higher the tropolone concentration used, the greater the inhibition of pigment formation by oxidation of the $o$-dihydrophenols investigated. Kahn \& Andrawis (1985a) suggest that tropolone and $o$-dihydroxyphenols compete for binding to the copper at the active site of the enzyme.

$o$-Dihydroxyphenols can be acted upon by the tyrosinase as well as by peroxidase and hydrogen peroxide, leading to the formation of $o$-quinones which then undergo rapid nonenzymatic conversion to polymeric pigments. Peroxidase can act both on 
monohydroxyphenols and o-dihydroxyphenols. Kahn (1985) documented that tropolone can aid in differentiating between tyrosinase and peroxidase activities since: (a) it is a very effective inhibitor of tyrosinase, (b) in the presence of hydrogen peroxide it can serve as a substrate for peroxidase (Khan \& Andrawis 1985b), (c) at concentrations that inhibit tyrosinase, it does not inhibit peroxidase activity, and (d) it inhibits tyrosinase activity even in the presence of hydrogen peroxidase. The tropolone inhibited also polyphenol oxidase in grape fruits (Valero et al. 1991), and in wounded hybrid poplar leaves (Constabel et al. 2000).

Fuerst et al. (2006) have studied the darkening of alkaline wheat noodles and found that the process was correlated with kernel polyphenol oxidase (PPO) activity. Tropolone substantially reduced PPO activity in cultivars with high activity of the enzyme, but did not inhibit the enzyme activity in the cultivars with very low PPO. Authors suggest that although PPO contributes substantially in darkening as a result of high levels of PPO in wheat cultivars, an additional unknown mechanism of darkening is probably also involved.

Among 14 tested inhibitors of polyphenol oxidase activity from artichoke (Cynara scolymus L.), the most effective inhibitor of the enzyme was tropolone (Dogan et al. 2005). Furthermore, it was found that this type of inhibition depends on the origin of the PPO studied and also on the substrate used.

Tropolone was the most effective or very effective inhibitor of polyphenol oxidase of other plants, like in a wounding-induced PPO from cowpea (Vigna unguiculata) seedlings (Pinto et al. 2008), Ocimum basilicum seedlings (Dogan et al. 2007), seeds of field bean (Dolichos lablab) (Paul \& Gowda 2000), various cultivars of aubergine (Solanum melongena) (Dogan et al. 2002), wheat bran (Yamasaki et al. 2008), or apricot fruits (Barret 2002). Broothaerts et al. (2000) showed that polyphenol oxidase reaction in transgenic apple and tobacco leaves was strongly inhibited by tropolone, a $\mathrm{Cu}$ competitor, and restored by the addition of $\mathrm{Cu}^{2+}$. Okumura et al. (2011) found that hinokitiol (B-thujaplicin) and tropolone definitely inhibited polyphenol oxidase and browning of apple sections and inhibited browning of shrimps (Penaeus indicus). For darkening or discoloration of shrimps during cold storage, tyrosinase is mainly responsible. Tropolone is also an effective inhibitor of polyphenol oxidase activity in hemolymph lysate samples of Sydney rock oysters (Saccostrea glomerata) (Aladaileh et al. 2007).

Takahashi et al. (2010) examined the inhibitory effects of three isomers of thujaplicins $(\alpha, \beta, \gamma)$ on mushroom tyrosinase activity and showed that all these compounds inhibit the enzyme activity in a dose dependent manner, and $\gamma$-thujaplicin was found to be the most potent inhibitor among them. Zhu et al. (2010) showed that hinokitiol effectively inhibited both cellular tyrosinase activity and melanin biosynthesis in B16 melanoma cells with significant cytotoxicity.

Various organs of Hippeastrum infected by Phoma narcissi, infested with mite Steneotarsonemus laticeps or mechanically wounded, produce a red pigment on the surface of injured tissues. Tropolone and hinokitiol greatly inhibited the formation of the pigment in wounded scales of Hippeastrum, proportionally to their concentration; using a concentration of $75.0 \mu \mathrm{g} \cdot \mathrm{cm}^{-3}$ almost completely inhibited the biosynthesis of this pigment. This was probably due to the strong inhibition of polyphenol oxidase activity and decline of the transformation of colourless flavans to oxidized red-coloured pigments after wounding of scales of Hippeastrum. The inhibitory effect of tropolone and hinokitiol on the red pigment formation in Hippeastrum tissues may also be caused by lowered biosynthesis and accumulation of jasmonates (Saniewski et al. 2007).

\section{THE EFFECTS OF TROPOLONE AND HINOKITIOL ON ETHYLENE PRODUCTION}

In wounded winter squash (Cucurbita maxima) mesocarps, both tropolone and hinokitiol inhibited ethylene production through suppression of 1-aminocyclopropane-1-carboxylate (ACC) synthase and oxidase (Rabbany \& Mizutani 1998). These two compounds at concentrations of 10 to $500 \mathrm{ppm}$ decreased ethylene production in young excised peach seeds and their inhibitory effects were proportionate to their concentrations (Mizutani et al. 1998a). 
The application of aqueous or gaseous tropolone and hinokitiol inhibited ethylene production and ACC oxidase activity in apple fruit plugs, but the addition of $\mathrm{Fe}^{2+}$ in the solution alleviated the inhibition (Mizutani et al. 1998b).

The mechanism of the inhibitory effect of tropolone and hinokitiol on ACC synthase and oxidase activities is unknown. Tropolone and hinokitiol, known as chelating agents forming complexes with iron, may limit $\mathrm{Fe}^{2+}$ for ACC oxidase activity, which requires the iron for its activation.

\section{ANTIBACTERIAL ACTIVITY OF TROPONOIDS}

In 1938 it was already shown that $\beta$-thujaplicin has a significant antibacterial activity against the tubercle bacillus (tuberculosis) and other bacteria. Tropolone and other unsubstituted troponoids itself are bacteriostatic and bactericidal for a wide range of bacterial species (Trust 1975; Trust \& Bartlett 1975).

Tropolone considerably delayed wilting of cut roses, Dendranthema grandiflora, Astilbe and Viburnum, mostly by blockade of wound-induced and bacteria-induced xylem (van Doorn \& Vaslier 2002; Loubaud \& van Doorn 2004). Tropolone at concentrations of 0.25 and $0.50 \mathrm{mM}$ was a very effective antibacterial compound in vase water of rose (Loubaud \& van Doorn 2004).

It was found that hinokitiol could also inhibit the proliferation of Salmonella enteritidis, Escherichia coli, Bacillus subtilis, Staphylococcus aureus, Klebsiella pneumoniae, and Ralstonia solanacearum to different extents; the antibacterial activity against $S$. enteritidis, E. coli, and B. subtilis was most effective (Zhu et al. 2010).

Zhao et al. (2009) demonstrated antibacterial activities of hinokitiol against heterotrophic bacteria, such as Sphingomonas paucimobilis and Brevundimonas vesicularis, which were isolated from hemodialysis fluid. The hinokitiol in concentrations below $10 \mu \mathrm{g} \cdot \mathrm{cm}^{-3}$ inhibited the growth of these bacteria incubated in optimal growth conditions. These authors suggested that hinokitiol may act as a safe and effective supplement for hot water disinfection in hemodialysis therapy.
Oh et al. (2011) showed that hinokitiol isolated from Thujopsis dolabrata exhibited a broad spectrum of antibacterial (S. aureus, B. subtilis, Micrococcus luteus, Proteus vulgaris, Salmonella typhimurium) and antifungal activity (Candida albicans, Aspergillus fumigatus, Trichophyton rubrum, T. mentagrophytes).

Burkholderia plantarii, a rice bacterial pathogen, produces tropolone as a phytotoxin and a virulence factor which causes seedling blight. Rice seedlings exposed to tropolone typically exhibit stunting, as a blight symptom similar to the rice seedlings, that have been infested with $B$. plantarii (Azegami et al. 1985). The tropolone-tolerant Trichoderma virens PS1-7 was found to be a marked competitor of pathogenic B. plantarii. The antagonistic effects exerted by $T$. virens PS1-7 against B. plantarii was found to be a major contributor to the repression of tropolone biosynthesis by the bacteria and protected rice seedlings which have been inoculated with it (Wang et al. 2013a). Recently, Wang et al. (2013b) demonstrated that carot-4-en-9, 10-diol released by $T$. virens PS1-7 acts as an interkingdom cell-to-cell signalling molecule against $B$. plantarii to repress tropolone production, as well as attenuate virulence on rice seedlings and induces pseudo-biofilm to the cells.

\section{ANTIFUNGAL ACTIVITY OF TROPONOIDS}

Numerous reports have described antifungal properties of troponoids. It was shown that tropolone strongly inhibited the growth of different white and brown rot fungi involved in wood biodegradation, including Coriolus (Trametes) versicolor, Phanerochaete chrysosporium, Poria placenta and Gloeophyllum trabeum on malt-agar, and antifungal activity of tropolone is similar to that of commercially available fungicides (Baya et al. 2001).

Diouf et al. (2002) showed that tropolone inhibition of the growth of $P$. placenta on malt-agar could be relieved by adding iron salts; these data are consistent with the hypothesis that $P$. placenta growth inhibition is a result of tropolone metal chelation, leading to a limitation of available iron. 
Fallik and Grinberg (1992) documented that hinokitiol inhibited in vitro spore germination and mycelial growth of Botrytis cinerea and Alternaria alternata. In general, Botrytis was more sensitive than Alternaria, and spore germination for both fungi was more sensitive than their mycelial growth. The mycelial growth of Botrytis was completely inhibited at a concentration of $250 \mu \mathrm{l} \cdot \mathrm{dm}^{-3}$, whereas inhibition of mycelial growth of Alternaria required $750 \mu \mathrm{l}^{\cdot} \mathrm{dm}^{-3}$ hinokitiol. A marked reduction in decay development was observed when commercially harvested eggplants and red peppers were dipped in hinokitiol solution at a concentration of $750 \mu \mathrm{l} \cdot \mathrm{dm}^{-3}$. A. alternata and B. cinerea were the main infectious agents that developed during storage and shelf-life on eggplant and red pepper fruits. Hinokitiol has been also used to control postharvest disease in peach (Sholberg \& Shimizu 1991). The effective dose of hinokitiol that reduced fungal spore germination by $50 \%\left(\mathrm{ED}_{50}\right)$ was $30.0,14.7$ and $18.1 \mu \mathrm{g} \cdot \mathrm{dm}^{-3}$, respectively, for B. cinerea, Monilinia fructicola and Rhizopus oryzae. The mycelium growth of these fungi was greatly inhibited by low concentrations of hinokitiol (Sholberg \& Shimizu 1991).

Aharoni et al. (1993) showed that hinokitiol at a concentration of $750 \mu \mathrm{g} \cdot \mathrm{cm}^{-3}$ in wax controlled the decay-causing fungi on 'Galia' melons (Cucumis melo cv. Reticulatus) and had no phytotoxic effect on the fruit. Hinokitiol at concentrations of 200 and $300 \mu \mathrm{g}^{\cdot} \mathrm{cm}^{-3}$ completely inhibited the mycelial growth of A. alternata and Fusarium spp., respectively.

Tropolone and hinokitiol inhibited the mycelium growth of Pythium aphanidermatum, Thanatephorus cucumeris, Fusarium solani, Botryotinia fuckeliana, Phomopsis obscurans, Colletotrichum lagenarium and $C$. orbiculare, and their minimum inhibitory concentration (MIC) values were in the range of 6.0-50.0 $\mu 1 \cdot \mathrm{dm}^{-3}$ (Morita et al. 2003).

Saniewska and Saniewski (2007) documented the inhibitory effect of tropolone and hinokitiol on the mycelium growth of Phoma narcissi in vitro, a pathogen of the species family Amaryllidaceae that applied preventively substantially inhibited the growth of the pathogen on excised scales and leaves of Hippeastrum.
Chedgy et al. (2007) identified in Thuja plicata six major troponoids, (-)-plicatic acid, $\gamma$-thujaplicin, B-thujaplicin, B-thujaplicinol, thujic acid, and methyl thujate. The growth of 11 fungal isolates from $T$. plicata (actinomycetes, basidiomycetes, zygomycetes) was inhibited to different degrees by the total extractives of T. plicata, with the highest activity of $\gamma$-thujaplicin and $\beta$-thujaplicin (Lim et al. 2007).

Besides tropolone and hinokitiol, from tissues of several Cupressaceae species another compounds with antifungal activities were isolated. $\alpha$-Thujaplicin, $\beta$-dolabrin, $\gamma$-thujaplicin and 4-acetyltropolone components of Thujopsis dolabrata var. hondai, showed strong antifungal activity against seven species of plant pathogenic fungi (Morita et al. 2004a, b), earlier tested by Morita et al. (2003). 4-Acetyltropolone also had strong antifungal activity on Daedalea dickinsii and Coriolus (Trametes) versicolor (Morita et al. 2002).

Tropolone and hinokitiol greatly inhibited the growth of Fusarium oxysporum f. sp. tulipae mycelium on the potato dextrose agar (Saniewska \& Jarecka 2008). Total inhibition of the mycelium growth took place by concentration of $100 \mu \mathrm{g} \cdot \mathrm{cm}^{-3}$ and $50 \mu \mathrm{g} \cdot \mathrm{cm}^{-3}$ for tropolone and hinokitiol, respectively.

Manter et al. (2006) demonstrated that wood chips, essential oil from the wood, and four individual compounds (nootkatin, carvacrol, valencene, nootkatone) from Alaska yellow-cedar (Chamaecyparis nootkatensis) heartwood strongly inhibit the germination of Phytophthora ramorum zoospores or sporangia, and reduce hyphal growth in culture. In further studies, ethyl acetate extracts from heartwood of seven western conifer trees and individual volatile compounds in the extracts were tested for antimicrobial activity against $P$. ramorum. Extracts from incense cedar (Calocedrus decurrens) and western redcedar (T. plicata) exhibited the strongest activity, followed by yellow-cedar ( $C$. nootkatensis), western juniper (Juniperus occidentalis) and Port-Orford-cedar (C. lawsoniana) with moderate activity, and no activity for Douglas-fir (Pseudotsuga menziesii) and redwood (Sequoia sempervirens) extracts (Manter et al. 2006, 2007a, b). Chemical composition of the extracts varied both 
qualitatively and quantitatively among the species with a total of 37 compounds identified by mass spectrometry. Of the 13 individual heartwood compounds bioassayed, three showed strong activity (hinokitiol, thymoquinone, and nootkatin), three expressed moderate activity (nootkatol, carvacrol and valencene-11, 12-diol), and other compounds had weak or no activity (Manter et al. 2007a, b). A field trial in California showed that heartwood chips from western redcedar (T. plicata) placed on the forest floor for 4 months under Umbellularia californica (California bay laurel) with symptoms of $P$. ramorum leaf blight significantly limited the accumulation of $P$. ramorum DNA in the litter layer, compared with heartwood chips from redwood (S. sempervirens) (Manter et al. 2007a, b).

Two antifungal compounds from the ethanolic extracts of Calocedrus macrolepis var. formosana (Florin) heartwood were isolated and identified as B-thujaplicin and $\gamma$-thujaplicin (Yen et al. 2008). Antifungal activities of those two compounds were evaluated against 15 different fungi. Both compounds exhibited very strong antifungal activity and broad antifungal spectrum against a wide variety of fungi such as wood decay fungi, pathogenic fungi and molds (Table 1). Using scanning electron microscope, severe cell wall collapse was observed on the hyphae and terminal chlamydospores of Laetiporus sulphureus after treatment with $ß$-thujaplicin, indicating that fungal cell wall might be disintegrated and leading to massive cytoplasm leakage (Yen et al. 2008).

Grohs and Kunz (1998) showed that tropolone at a concentration of $10^{-3} \mathrm{M}$ arrested the growth of Penicillium glabrum and Trichoderma harzianum, and was fungistatic to the growth of Aureobasidium pullulans var. melanogenum at a concentration of $10^{-5} \mathrm{M}$.

Yu and Komada (1999) documented that hinoki (Chamaecyparis obtusa) bark, applied as a substrate for growing tomato, greatly reduced the incidences of fusarium crown and root rot (Fusarium oxysporum f. sp. radicis-lycopersici) and bacterial wilt (Pseudomonas solanacearum). Ethanol extracts of the bark greatly inhibited Fusarium and Pseudomonas.
Table 1. Concentration of troponoids which inhibited $50 \%$ of growth $-\mathrm{IC}_{50}\left(\mu \mathrm{g} \cdot \mathrm{cm}^{-3}\right)$, and minimal inhibitory concentration, MIC $\left(\mu \mathrm{g} \cdot \mathrm{cm}^{-3}\right)$ against wood decay fungi, pathogenic fungi and molds (Yen et al. 2008)

\begin{tabular}{lrrrr}
\hline \multirow{2}{*}{ Fungal strains } & \multicolumn{3}{c}{$\beta$-Thujaplicin } & $\gamma$-Thujaplicin \\
\cline { 2 - 5 } & $\mathrm{IC}_{50}$ & $\mathrm{MIC}$ & $\mathrm{IC}_{50}$ & $\mathrm{MIC}$ \\
\hline \multicolumn{1}{c}{ White rot } & & & & \\
\hline Lenzites betulina & 2.2 & 10.0 & 7.9 & 10.0 \\
Pycnoporus coccineus & 8.7 & 15.0 & 12.1 & 25.0 \\
Trametes versicolor & 14.4 & 25.0 & 16.5 & 30.0 \\
Schizophyllum commune & 18.6 & 35.0 & 24.2 & 40.0 \\
\hline \multicolumn{1}{c}{ Brown rot } & & & & \\
\hline Laetiporus sulphureus & 0.2 & 5.0 & 0.6 & 5.0 \\
Phaeolus schweinitzii & 0.8 & 5.0 & 1.4 & 10.0 \\
Gloeophyllum trabeum & 1.2 & 10.0 & 2.3 & 10.0 \\
Fomitopsis pinicola & 3.3 & 10.0 & 7.4 & 15.0 \\
\hline \multicolumn{1}{c}{ Tree pathogenic fungi } & & & & \\
\hline Ganoderma australe & 3.2 & 10.0 & 6.7 & 15.0 \\
Pestalotiopsis funerea & 17.7 & 25.0 & 20.5 & 35.0 \\
Fusarium solani & 18.1 & 40.0 & 23.6 & 45.0 \\
Colletotrichum gloeo- & 22.3 & 45.0 & 23.8 & 50.0 \\
sporioides & & & & \\
\hline \multicolumn{1}{c}{ Mold } & 10.2 & 20.0 & 14.8 & 25.0 \\
\hline Trichoderma viride & 14.3 & 30.0 & 17.6 & 30.0 \\
Penicillium citrinum & 24.5 & 50.0 & 26.5 & 50.0 \\
Aspergillus niger & & & & \\
\hline & & & & \\
\hline
\end{tabular}

Li et al. (2012) showed that natural and synthetic hinokitiol, and also water soluble hinokitiol (hinokitiol sodium salt) exhibited similar antifungal activity against Aspergillus niger and Penicillium citrinum on yellow poplar (Liriodendron tulipifera) sapwood wafers. Fungal attack by Gloeophyllum trabeum or Trametes versicolor was completely inhibited in soil block tests in Populus ussuriensis wood treated with natural and synthetic hinokitiol and hinokitiol sodium salt.

Hinokitiol inhibited the growth of Penicillium expansum, which grew on the plates of thirteen types of jam, when applied by mixing the jam with hinokitiol at concentrations of a range $0.005 \%$ to $0.1 \%$, depending on the kind of jam (Katsumata et al. 2003).

Recently, Davison et al. (2012) demonstrated genetic, molecular, and biochemical basis of fungal tropolone biosynthesis, using the fungus Talaromyces stipitatus (previously known as Penicillium stip- 
itatum). The fungus Talaromyces stipitatus produces stipitatic acid (Fig. 3) (Birkinshaw et al. 1942). Davison et al. (2012) found that three oxidative enzymes, TropB, TropC and TropD, were key genes in the biosynthetic process leading to the production of the stipitatic acid, and potential tropolone biosynthetic clusters were detected also in other fungi (Acremonium strictum, Metarhizium anisopliae, Aspergillus nidulans, A. oryzae, Leptosphaeria maculans, Monascus purpureus, Coccidioides immitis, and Colletotrichum higginsianum).

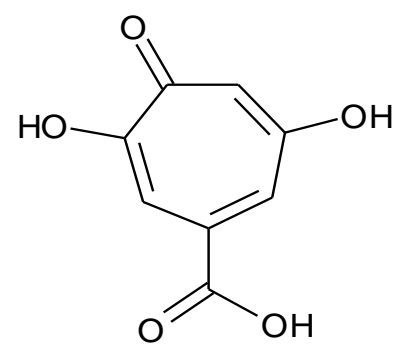

Fig. 3. Chemical structure of stipitatic acid (3,6-dihydroxy-4-oxo-cyclo-hepta-triene-carboxylic acid), a troponoid isolated from mold $T$. stipitatus (P. stipitatum) (Davison et al. 2012; Crawford \& Clardy 2012)

Thus, hinokitiol and tropolone are very promising candidates for postharvest decay control in a range of fruits, vegetables, and ornamental plants. It is well known that food packages can be made to be antimicrobial active by incorporation and immobilization of antimicrobial agents or by surface modification and surface coating. Suppakul et al. (2003) presented active packaging technologies with an emphasis on antimicrobial packaging and its applications, and hinokitiol is considered to be one antimicrobial agent. Hinokitiol has been used as a food additive for more than 20 years in Japan (Ooka et al. 2012).

\section{INSECTICIDAL AND ACARICIDAL ACTIVITY OF TROPONOIDS}

Tropolone, hinokitiol and some other troponoids have insecticidal properties. Tropolone and hinokitiol showed strong insecticidal activity on $T y$ rophagus putrescentiae and Dermatophagoides farinae (Morita et al. 2003). The insecticidal activity of both compounds was higher than that of N,N- diethyl- $m$-toluamide (DEET), used as positive control. DEET is the most common active ingredient in insect repellents. It provides protection against mosquito bites, flea bites, chiggers, and many other biting insects.

Hori (2004a, b) documented that hinokitiol had a stronger repellency against the cigarette beetle, Lasioderma serricorne (Fabricius) (Coleoptera: Anobiidae) than chemicals and essential oils known as repellents. However, insecticidal activity of hinokitiol against the cigarette beetle was weak (Hori 2004a). The repellency of the other troponoid compounds, tropone and tropolone, were weaker than hinokitiol.

Earlier, Ahn et al. (1998) showed insecticidal and acaricidal activity of components of Thujopsis dolabrata var. hondai sawdust against the arthropod pests, Reticulitermes speratus, Callosobruchus chinensis, Sitophilus oryzae, Plutella xylostella, Myzus persicae, Blattella germanica, Tetranychus urticae and Lasioderma serricorne. They concluded that the active component of Thujopsis dolabrata var. hondai sawdust was carvacrol.

$\alpha$-Thujaplicin indicated strong insecticidal activity against $R$. speratus and also had clear acaricidal activity against $D$. farinae (Morita et al. 2004b). The acaricidal activity of hinokitiol, $\gamma$-thujaplicin and ß-dolabrin and tropolone on T. putrescentiae and Coptotermes formosanus was reported earlier (Inamori et al. 2000; Morita et al. 2003).

Shimizu and Hori (2009) compared the repellency and toxicity against adzuki bean beetles (Callosobruchus chinensis) among five troponoid compounds (tropiliden, tropolone, $\alpha$-thujaplicin, $\beta$-thujaplicin and $\gamma$-thujaplicin). $\gamma$-Thujaplicin showed the highest repellency and highest toxicity against the beetles among the tested compounds, while the repellency of tropiliden was quite low. Tropolone showed the highest toxicity while its repellency was relatively low. Tropolone, $\alpha$-thujaplicin, $\beta$-thujaplicin and $\gamma$-thujaplicin showed similar toxicities that were lower than that of tropolone. The mixture of $\gamma$-thujaplicin and B-thujaplicin showed extremely high repellency to the beetles; however, the toxicity of the mixture was a little lower than that of $\gamma$-thujaplicin and was similar to that of B-thujaplicin (Shimizu \& Hori 2009). The authors concluded that 
the mixture is a promising repellent and it can be put to practical use. B-Thujaplicin is also very repellent to the cigarette beetle (Lasioderma serricorne) and can prevent the beetles from invading stored tobacco (Hori 2004b, 2005).

Leaf oils of Chamaecyparis obtusa and Thuja orientalis show promise as natural larvicidal activities against two mosquito species, Aedes aegypti and Culex pipiens pallens (Jeon et al. 2005). Essential oils obtained from $C$. obtusa and T. orientalis have acaricidal activity against stored food and house dust mites (Sung et al. 2004). Essential oil from C. obtusa was toxic against Dermatophagoides farinae and $D$. pteronyssinus, and $T$. orientalis against Tyrophagus putrescentiae. Essential oil from leaves of $C$. obtusa showed insecticidal activities against C. chinensis and Sitophilus oryzae (Park et al. 2003). Essential oil of Thujopsis dolabrata var. hondai and its two constituents, thymoquinone and hinokitiol, were found to be active against Plasmodium falciparum in vitro and in vivo studies confirmed the anti-plasmodial potential of subcutaneously administered hinokitiol against rodent $P$. berghei (Fujisaki et al. 2012).

\section{BIOTRANSFORMATION OF B-THUJAPLICIN BY CULTURED PLANT CELLS}

Thujaplicins and similar compounds may have potential for use in medicine. In view of these considerations, the conditions for its production by cell cultures have been investigated (Zhao et al. 2006). In cell cultures, $\beta$-thujaplicin production can be stimulated by a yeast elicitor, methyl jasmonate, and other stresses. Elicitor-treated cultures accumulate high amounts of $\beta$-thujaplicin at early stages of incubation (Yamada et al. 2003).

Madar et al. (1995) isolated from the bark of Cupressus sempervirens two antifungal terpenoids, 6-isopropyltropolone B-glucoside and 5-(3-hydroxy3-methyl-trans-1-butenyl)-6-isopropyl-tropolone ß-glucoside, produced after infection of Diplodia pinea $\mathrm{f}$. sp. cupressi. These tropolone glucosides inhibited in vitro germination of spores of $D$. pinea f. sp. cupressi. These compounds also inhibited in vitro germination of spores of Seiridium cardinale, A. alternata and Verticillium dahliae. Since synthesis of the antifungal terpenoid compounds were induced in response to fungal infection, those compounds can be defined as phytoalexins (Madar et al. 1995).

Furuya et al. (1997) showed that B-thujaplicin added to cell suspension culture of Eucalyptus perriniana was transformed into four new compounds: 4-isopropyltropolone $2-O-\beta-\mathrm{D}$-glucoside, 4-isopropyltropolone 2-O- $\beta$-D-gentiobioside, 6-iso-propyltropolone $2-O-\beta-\mathrm{D}$-glucoside, and 6-iso-propyltropolone 2-O-B-D-gentiobioside, after 7 days of the experiment. Also the cultured plants cells of Nicotiana tabacum transformed B-thujaplicin to four new, similar products after 7 days of incubation, similarly to cell culture of E. perriniana (Kwon et al., 2008). It was also observed that the ratio of biotransformation was higher in iron-deficient medium, than in the medium containing iron ions (Furuya et al. 1997; Kwon et al. 2008).

\section{HINOKITIOL AND TROPOLONE AND THEIR DERIVATIVES AGAINST HUMAN DISEASES}

Hinokitiol and tropolone are compounds that have been most rigorously investigated because of their activity against human tumor cells and a variety of microorganisms that cause diseases of humans. Thujaplicin and tropolone form complex salts with many ions: $\mathrm{Ca}, \mathrm{Fe}, \mathrm{Ag}, \mathrm{Cu}, \mathrm{Mn}$, Co etc. Such complex forms are more stable than starting compounds (Fig. 4). $\beta$-Thujaplicin, tropolone and related troponoids display antiviral and anticancer activities (Budihas et al. 2005; Mesa-Siverio et al. 2003; Yamato et al. 1992; Ooka et al. 2012; Hu et al. 2013; Wakabayashi et al. 2003; Liu \& Yamauchi 2006, 2009; Najda-Bernatowicz et al. 2010).

Natural tropolone shows numerous biological activities while its synthetic analogues were found to exhibit the important medical properties. There are many publications in the scientific literature dedicated to the synthesis of important analogs of hinokitiol and tropolone (Koufaki et al. 2010; Oblak et al. 2012).

Chemical synthesis of tropolone has been studied for a long time because of the great interest of its synthetic analogues due to their anticancer and antiischemic properties. About 60 years ago, one of the first methods for the synthesis of tropolones through 
the insertion of methylene to substituted benzene was described (Fig. 5) (Doering \& Knox 1953).

Now there are several contemporary methods for the chemical synthesis of tropolone. The first involves bromination of 1,2-cycloheptanedione with

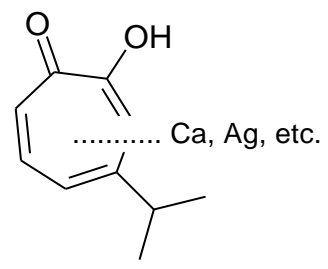

Fig. 4. Structure of calcium and other complex salts of the $\beta$-thujaplicin (hinokitiol)

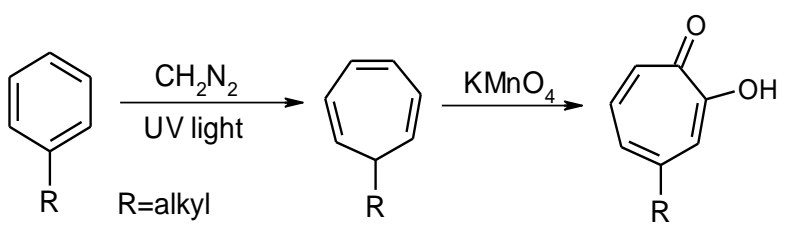

Fig. 5. Chemical synthesis of various tropolones by insertion of methylene to benzene ring

\section{REFERENCES}

Aharoni Y., Copel A., Fallik E. 1993. Hinokitiol (Bthujaplicin), for postharvest decay control on 'Galia' melons. New Zeal. J. Crop Hort. 21: $165-$ 169. DOI: 10.1080/01140671.1993.9513763.

Ahn Y.J., Lee S.B., Lee H.S., Kim G.H. 1998. Insecticidal and acaricidal activity of carvacrol and ß-thujaplicin derived from Thujopsis dolabrata var. hondai sawdust. J. Chem. Ecol. 24: 81-90. DOI: 10.1023/A:1022388829078.

Aladaileh S., Rodney P., Nair S.V., Raftos D.A. 2007. Characterization of phenoloxidase activity in Sydney rock oysters (Saccostrea glomerata). Comp. Biochem. Physiol. B 148: 470-480. DOI: 10.1016/j.cbpb.2007.07.089.

Azegami K., Nishiyama K., Watanabe Y., Suzuki T., Yoshida M., Nase K., Toda S. 1985. Tropolone as a root growth-inhibitor produced by a plant pathogenic Pseudomonas sp. causing seedling blight of rice. Ann. Phytopathol. Soc. Jpn. 51: 315-317.

Barret R. 2002. Characterisation of apricot polyphenoloxidase during fruit development. Adelaide Research and Scholarship. http:/hdl.handle.net/2440/37978.
$\mathrm{N}$-bromosuccinimide (NBS) followed by dehydrohalogenation at elevated temperatures (Fig. 6). The other is based on acyloin condensation of the ethyl ester of heptanedioic acid followed by oxidation by bromine (Fig. 7).

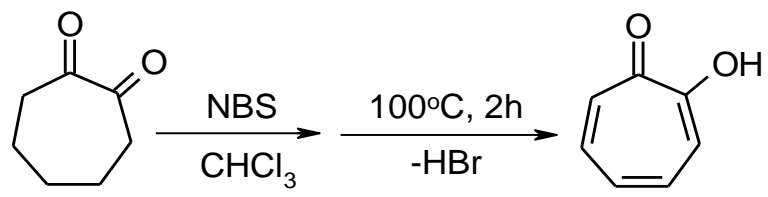

Fig. 6. Chemical synthesis of tropolone by bromination followed by dehydrohalogenation

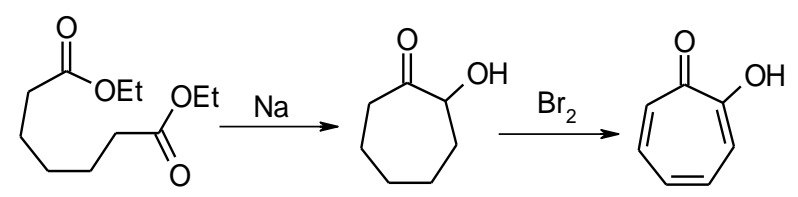

Fig. 7. Chemical synthesis of tropolone via acyloin condensation and oxidation with bromine

Baya M., Soulounganga P., Gelhaye E., Gérardin P. 2001. Fungicidal activity of $\beta$-thujaplicin analogues. Pest Manag. Sci. 57: 833-838. DOI: 10.1002/ps.379.

Bentley R. 2008. A fresh look at natural tropolonoids. Nat. Prod. Rep. 25: 118-138. DOI: 10.1039/B711474E.

Birkinshaw J.H., Chambers A.R., Raistrick H. 1942. Studies in the biochemistry of microorganisms. 70Stipitatic acid, $\mathrm{C}_{8} \mathrm{H}_{6} \mathrm{O}_{5}$, a metabolic product of Penicillium stipitatum Thorn. Biochem. J. 36: 242-251.

Broothaerts W., McPherson J., Li B., Randall E., Lane W.D., Wiersma P.A. 2000. Fast apple (Malus $\times$ domestica) and tobacco (Nicotiana tabacum) leaf polyphenol oxidase activity easy for screening transgenic plants. J. Agric. Food Chem. 48: 5924-5928. DOI: 10.1021/jf000599m.

Budihas S.R., Gorshkova I., Gaidamakov S., Wamiru A., Bona M.K., Parniak M.A., Crouch R.J., McMahon J.B., Beutler J.A., Le Grice S.F.J. 2005. Selective inhibition of HIV-1 reverse transcriptase-associated ribonuclease $\mathrm{H}$ activity by hydroxylated tropolones. Nucleic Acids Res. 33: 1249-1256. DOI: 10.1093/nar/gki268.

Chedgy R.J., Daniels C.R., Kadla J., Breuil C. 2007. Screening fungi tolerant to Western red cedar 
(Thuja plicata Donn) extractives. Part I. Mild extraction by ultrasonication and quantification of extractives by reverse-phase HPLC. Holzforschung 61: 190-194. DOI: 10.1515/HF.2007.033.

Constabel C.P., Yip L., Patton J.J., Christopher M.E. 2000. Polyphenol oxidase from hybrid poplar. Cloning and expression in response to wounding and herbivory. Plant Physiol. 124: 285-296. DOI: 10.1104/pp.124.1.285.

Cox R.J., Al-Fahad A. 2013. Chemical mechanisms involved during the biosynthesis of tropolones. Curr. Opin. Chem. Biol. 17: 532-536. DOI: 10.1016/j.cbpa.2013.06.029.

Crawford J.M., Clardy J. 2012. Microbial genome mining answers longstanding biosynthetic questions. Proc. Natl. Acad. Sci. USA 109(20): 7589-7590. DOI: 10.1073/pnas.1205361109.

Davison J., Al Fahad A., Cai M., Song Z., Yehia S.Y., Lazarus C.M., Bailey A.M., Simpson T.J., Cox R.J. 2012. Genetic, molecular, and biochemical basis on fungal tropolone biosynthesis. Proc. Natl. Acad. Sci. USA 109(20): 7642-7647. DOI: 10.1073/pnas.1201469109.

Diouf P.N., Delbarre N., Perrin D., Gérardin P., Rapin C., Jacquot J.P., Gelhaye E. 2002. Influence of tropolone on Poria placenta wood degradation. Appl. Environ. Microbiol. 68: 4377-4382. DOI: 10.1128/AEM.68.9.4377-4382.2002.

Doering W.E., Knox L.H. 1953. Synthesis of substituted tropolones. J. Am. Chem. Soc. 75: 297-303. DOI: 10.1021/ja01098a014.

Dogan M., Arslan O., Dogan S. 2002. Substrate specificity, heat inactivation and inhibition of polyphenol oxidase from different aubergine cultivars. Int. J. Food Sci. Tech. 37: 415-423. DOI 10.1046/j.1365-2621.2002.00580.x.

Dogan S., Turan P., Dogan M., Alkan M., Arslan O. 2007. Inhibition kinetic of Ocimum basilicum L. polyphenol oxidase. Int. J. Chem. Reac. Eng. 5: 1-12. DOI: $10.2202 / 1542-6580.1465$.

Dogan S., Turan Y., Erturk H., Arslan O. 2005. Characterization and purification of polyphenol oxidase from artichoke (Cynara scolymus L.). J. Agric. Food Chem. 53: 776-785. DOI: 10.1021/jf051646j.

van Doorn W.G., Vaslier N. 2002. Wounding-induced xylem occlusion in stems of cut chrysanthemum flowers, roles of peroxidase and cathechol oxidase. Postharvest Biol. Technol. 26: 275-284. DOI: 10.1016/S0925-5214(02)00039-X.

Fallik E., Grinberg S. 1992. Hinokitiol: a natural substance that controls postharvest diseases in eggplant and pepper fruits. Postharvest Biol. Technol. 2: 137-144. DOI: 10.1016/0925-5214(92)90016-I.
Fuerst E.P., Anderson J.V., Morris C.F. 2006. Delineating the role of polyphenol oxidase in the darkening of alkaline wheat noodles. J. Agric. Food Chem. 54: 2378-2384. DOI: 10.1021/jf0526386.

Fuji R., Ozaki K., Ino W., Watanabe H. 1995. Hinokitiol production in suspension cells of Thujopsis dolabrata var. hondai Makio. Plant Tiss. Cult. Lett. 12: 55-61. DOI: 10.5511/plantbiotechnology1984.12.55.

Fujisaki R., Kamei K., Yamamura M., Nishiya H., Inouye S., Takahashi M., Abe S. 2012. In vitro and in vivo anti-plasmodial activity of essential oils, including hinokitiol. Southeast Asian J. Trop. Med. Public Health 43: 270-279.

Furuya T., Asada Y., Matsuura Y., Mizobata S., Hamada H. 1997. Biotransformation of B-thujaplicin by cultured cells of Eucalyptus perriniana. Phytochemistry 46: 1355-1358. DOI: 10.1016/S0031-9422(97)00463-9.

Grohs B.-M., Kunz B. 1998. Fungitoxicity of chemical analogs with heartwood toxins. Curr. Microbiol. 37: 67-69. DOI: 10.1007/s002849900340.

Haluk J.-P., Roussel C. 2000. Caractérisation et origine des tropolones responsables de la durabilité naturelle des Cupressacées. Application potentielle en préservation du bois. Ann. For. Sci. 57: 819-829.

Haluk J.P., Roussel-Bousta C. 2003. Biosynthèse de tropolones dans les cals et les suspension cellulaires à partir d'ébauches foliaires de plantules de Thuja plicata Donn. Ann. For. Sci. 60: 271-276.

Harada T., Harada E., Sakamoto R., Ashitani T., Fujita K., Kuroda K. 2012. Regio- and substrate- specific oxidative metabolism of terpinolene by cytochrome P450 monooxygenases in Cupressus lusitanica cultured cells. Am. J. Plant Sci. 3: 268-275. DOI: 10.4236/ajps.2012.32032.

Hori M. 2005. Development of repellent strips for controlling the cigarette beetle, Lasioderma serricorne (Fabricius) (Coleoptera: Anobiidae). Appl. Entomol. Zool. 40: 373-377.

Hori M. 2004a. Evaluation of the practicability of hinokitiol as a repellent against the cigarette beetle, $L a$ sioderma serricorne (Fabricius) (Coleoptera: Anobiidae). Appl. Entomol. Zool. 39: 699-704.

Hori M. 2004b. Repellency of hinokitiol against the cigarette beetle, Lasioderma serricorne (Fabricius) (Coleoptera: Anobiidae). Appl. Entomol. Zool. 39: 521-526.

Hu Y., Cheng X., Cao F., Huang A., Tavis J.E. 2013. ß-Thujaplicinol inhibits hepatitis $\mathrm{B}$ virus replication by blocking the viral ribonuclease $\mathrm{H}$ activity. Antiviral Res. 99: 221-229. DOI: 10.1016/j.antiviral.2013.06.007. 
Inada S., Tsutsumi Y., Sakai K. 1993. Elicitor of the ß-thujaplicin accumulation in callus cultures of Cupressus lusitanica. J. Fac. Agr. Kyushu U. 38: 119-126.

Inamori Y., Sakagami Y., Morita Y., Shibata M., Sugiura M., Kumeda Y., Okabe T., Tsujibo H., Ishida N. 2000. Antifungal activity of hinokitiol-related compounds on wood-rotting fungi and their insecticidal activities. Biol. Pharm. Bull. 23: 995-997. DOI: 10.1248/bpb.23.979.

Itose R., Sakai K. 1997. Improved culture conditions for the production of $\beta$-thujaplicin by suspension cell cultures of Cupressus lusitanica. Plant Biotechnol. 14: 163-167.

Jeon J.-H., Lee S.-H., Kim M.-K., Lee H.-S. 2005. Larvicidal activity of Chamaecyparis obtusa and Thuja orientalis leaf oils against two mosquito species. Agr. Chem. Biotechnol. 48: 26-28.

Kahn V. 1985. Tropolone - a compound that can aid in differentiating between tyrosinase and peroxidase. Phytochemistry 24: 915-920. DOI: 10.1016/S00319422(00)83152-0.

Kahn V., Andrawis A. 1985a. Inhibition of mushroom tyrosinase by tropolone. Phytochemistry 24: 905908. DOI: 10.1016/S0031-9422(00)83150-7.

Kahn V., Andrawis A. 1985b. Tropolone as a substrate for horseradish peroxidase. Phytochemistry 24: 909-913. DOI: 10.1016/S0031-9422(00)83151-9.

Katsumata R., Ikue Y., Noriko N., Kanako M., Yutaka K., Kenji T., Kan K. 2003. Preservation of jams employing hinokitiol. J. Antibact. Antifung. Agents 31: 59-67.

Kim Y.-J., Uyama H. 2005. Tyrosinase inhibitors from natural and synthetic sources: structure, inhibition mechanism and perspective for the future. Cell. Mol. Life Sci. 62: 1707-1723. DOI: 10.1007/s00018-005-5054-y.

King M.V., de Vries J.L., Pepinsky R. 1952. An x-ray diffraction determination of the chemical structure of colchicine. Acta Cryst. B 5: 437-440. DOI: 10.1107/S0365110X52001313.

Koufaki M., Theodorou E., Alexi X., Nikoloudaki F., Alexis M.N. 2010. Synthesis of tropolone derivatives and evaluation of their in vitro neuroprotective activity. Eur. J. Med. Chem. 45: 1107-1112. DOI: 10.1016/j.ejmech.2009.12.006.

Kwon S., Shimoda K., Hamada H., Ishihara K., Masuoka N., Hamada H. 2008. High production of B-thujaplicin glycosides by immobilized plant cells of Nicotiana tabacum. Acta Biol. Hung. 59: 347-355. DOI: 10.1556/ABiol.59.2008.3.8.
Li S., Freitag C.M., Morrell J.J., Okabe T. 2012. Antifungal effects of hinokitiol and its sodium salt for wood protection. BioRes. 7: 5312-5318.

Lim Y.W., Chedgy R.J., Amirthalingam S., Breuil C. 2007. Screening fungi tolerant to Western red cedar (Thuja plicata Donn) extractives. Part 2. Development of a feeder strip assay. Holzforschung 61: 195-200. DOI: 10.1515/HF.2007.034.

Liu S., Yamauchi H. 2006. Hinokitiol, a metal chelator derived from natural plants, suppresses cell growth and disrupts androgen receptor signaling in prostate carcinoma cell lines. Biochem. Biophys. Res. Commun. 351: 26-32. DOI: 10.1016/j.bbrc.2006.09.166.

Liu S., Yamauchi H. 2009. p-27Associated G1 arrest induced by hinokitiol in human malignant melanoma cells is mediated via down-regulation of $\mathrm{pRb}$, Skp2 ubiquitin ligase, and impairment of Cdk2 function. Cancer Lett. 286: 240-249. DOI: 10.1016/j.canlet.2009.05.038.

Loubaud M., van Doorn W.G. 2004. Wound-induced and bacteria-induced xylem blockage in roses, Astilbe and Viburnum. Postharvest Biol. Technol. 32: 281-288. DOI: 10.1016/j.postharvbio.2003.12.004.

Madar Z., Gottlieb H.E., Cojocarn M., Riov J., Solel Z., Sztejnberg A. 1995. Antifungal terpenoids produced by cypress after infection by Diplodia pinea f. sp. cupressi. Phytochemistry 38: 351-354. DOI: 10.1016/0031-9422(94)00575-E.

Manter D.K., Karchesy J.J., Kelsey R.G. 2006. The sporicidal activity of yellow-cedar heartwood, essential oil and wood constituents towards Phytophthora ramorum in culture. For. Path. 36: 297-308. DOI: 10.1111/j.1439-0329.2006.00461.x.

Manter D.K., Kelsey R.G., Karchesy J.J. 2007a. Antimicrobial activity of extractable conifer heartwood compounds toward Phytophthora ramorum. J. Chem. Ecol. 33: 2133-2147. DOI: 10.1007/s10886-007-9368-0.

Manter D.K., Kelsey R.G., Karchesy J.J. 2007b. Antimicrobial activity of extracts and select compounds in the heartwood of seven western conifers toward Phytophthora ramorum. Proceedings of the Sudden Oak Death Third Science Symposium, March 5-9, 2007, Santa Rosa, California, pp. 375-378.

Marshall M.R., Kim J., Wei C.-I. 2000. Enzymatic browning in fruits, vegetables and seafoods. FAO, pp. 1-49.

Mesa-Siverio D., Estévez-Braun A., Ravelo Á.G., Murguia J.R., Rodríguez-Afonso A. 2003. Novel DNAdamaging tropolone derivatives from Goupia glabra. Eur. J. Org. Chem. 2003: 4243-4247. DOI: 10.1002/ejoc.200300284. 
Mizutani F., Rabbany A.B.M.G., Akiyoshi H. 1998a. Inhibition of ethylene production by tropolone compounds in young excised peach seeds. J. Jpn. Soc. Hortic. Sci. 67: 166-169.

Mizutani F., Rabbany A.B.M.G., Akiyoshi H. 1998b. Inhibition of ethylene production and 1-aminocyclopropane-1-carboxylate oxidase activity by tropolones. Phytochemistry 48: 31-34. DOI: 10.1016/S0031-9422(97)01093-5.

Morita Y., Matsumura E., Okabe T., Fukui T., Ohe T., Ishida N., Inamori Y. 2004a. Biological activity of ß-dolabrin, $\gamma$-thujaplicin, and 4-acetyltropolone, hinokitiol - related compounds. Biol. Pharm. Bull. 27: 1666-1669.

Morita Y., Matsumura E., Okabe T., Fukui T., Shibata M., Sugiura M., Ohe T., Tsujibo H., Ishida N., Inamori Y. 2004b. Biological activity of $\alpha$-thujaplicin, the isomer of hinokitiol. Biol. Pharm. Bull. 27: 899-902.

Morita Y., Matsumura E., Okabe T., Shibata M., Sugiura M., Ohe T., Tsujibo H., Ishida N., Inamori Y. 2003. Biological activity of tropolone. Biol. Pharm. Bull. 26: 1487-1490.

Morita Y., Matsumura E., Tsujibo H., Yasuda M., Okabe T., Sakagami Y., Kumeda Y., Ishida N., Inamori Y. 2002. Biological activity of 4-acetyltropolone, the minor component of Thujopsis dolabrata Sieb. et Zucc. hondai Mak. Biol. Pharm. Bull. 25: 981-985.

Najda-Bernatowicz A., Krawczyk M., StankiewiczDrogoń A., Bretner M., Boguszewska-Chachulska A.M. 2010. Studies on the anti-hepatitis $C$ virus activity of newly synthesized tropolone derivatives: identification of NS3 helicase inhibitors that specifically inhibit subgenomic HCV replication. Bioorg. Med. Chem. 18: 5129-5136. DOI: 10.1016/j.bmc.2010.05.066.

Oblak E.Z., Bolstad E.S., Ononye S.N., Priestley N.D., Hadden M.K., Wright D.L. 2012. The furan route to tropolones: probing the antiproliferative effects of $\beta$-thujaplicin analogs. Org. Biomol. Chem. 10(43): 8597-8604. DOI: 10.1039/C2OB26553B.

Oh I., Yang W.-Y., Park J., Lee S., Mar W., Oh K.-B., Shin J. 2011. In vitro $\mathrm{Na}^{+} / \mathrm{K}^{+}$-ATPase inhibitory activity and antimicrobial activity of sesquiterpenes isolated from Thujopsis dolabrata. Arch. Pharm. Res. 34: 2141-2147. DOI: 10.1007/s12272-011-1218-5.

Okumura S., Hoshino M., Joshita K., Nishinomiya T., Murata M. 2011. Hinokitiol inhibits polyphenol oxidase and enzymatic browning. Food Sci. Technol. Res. 17: 251-256.
Ono M., Asai T., Watanabe H. 1998. Hinokitiol production in a suspension culture of Calocedrus formosana Florin. Biosci. Biotechnol. Biochem. 62: 1653-1659.

Ooka S., Sato T., Arito M., Nakano H., Takakuwa Y., Suematsu N., Okamoto K., Kurokawa M., Ozaki S., Kato T. 2012. The effects of hinokitiol on human cells revealed by a proteomic approach. Inflamm. Regen. 32: 137-143.

Park I.K. Lee S.G., Choi D.H., Park J.D., Ahn Y.J. 2003. Insecticidal activities of constituents identified in the essential oil from leaves Chamaecyparis obtusa against Callosobruchus chinensis (L.) and Sitophilus oryzae (L.). J. Stored Prod. Res. 39: 375-384. DOI: 10.1016/S0022-474X(02)00030-9.

Paul B., Gowda L.R. 2000. Purification and characterization of a polyphenol oxidase from the seeds of field bean (Dolichos lablab). J. Agric. Food Chem. 48: 3839-3846. DOI: 10.1021/jf000296s.

Pinto M.S.T., Siqueira F.P., Oliveira A.F.A., Fernandes K.V.S. 2008. A wounding-induced PPO from cowpea (Vigna unguiculata) seedlings. Phytochemistry 69: 2297-2302. DOI: 10.1016/j.phytochem.2008.06.003.

Rabbany A.B.M.G., Mizutani F. 1998. Effect of tropolone and hinokitiol on in vitro activities of 1-aminocyclopropane-carboxylate synthase and oxidase in wounded winter squash mesocarps. J. Jpn. Soc. Hortic. Sci. 67: 213-215.

Saniewska A., Jarecka A. 2008. The inhibitory effect of tropolone and hinokitiol on the growth and development of Fusarium oxysporum f. sp. tulipae. Phytopathol. Pol. 50: 33-41.

Saniewska A., Saniewski M. 2007. The inhibitory effect of tropolone and hinokitiol on the mycelium growth of Phoma narcissi in vitro. Acta Agrobot. 60: 107-112.

Saniewski M., Saniewska A., Horbowicz M., Kanlayanarat S. 2007. The inhibitory effect of hinokitiol and tropolone on reddish colouration in mechanically wounded scales of Hippeastrum $\times$ hybr. Hort. and on the development of Phoma narcissi, the pathogen of Hippeastrum. Acta Hort. 755: 533-542.

Saniewski M., Saniewska A., Kanlayanarat S. 2007. Biological activities of tropolone and hinokitiol: the tools in plant physiology and their use. Acta Hort. 755: 133-142.

Shimizu C., Hori M. 2009. Repellency and toxicity of troponoid compounds against the adzuki bean beetle, Callosobruchus chinensis (L.) (Coleoptera: Bruchidae). J. Stored Prod. Res. 45: 49-53. DOI: 10.1016/j.jspr.2008.08.001. 
Sholberg P.L., Shimizu B.N. 1991. Use of the natural plant products, hinokitiol to extend shelf-life of peaches. Can. Inst. Food Sci. Technol. J. 24: 273 277. DOI: 10.1016/S0315-5463(91)70164-8.

Sung B.K., Kim M.K., Lee S.H., Son J.G., Lee H.S. 2004. Acaricidal activity of essential oils derived from 10 Cupressaceae species against stored food and house dust mites. Food Sci. Biotechnol. 13: 376-380.

Suppakul P., Miltz J., Sonneveld K., Bigger S.W. 2003. Active packaging technologies with an emphasis on antimicrobial packaging and its applications. J. Food Sci. 68: 408-420. DOI: 10.1111/j.1365-2621.2003.tb05687.x.

Takahashi S., Kamiya T., Saeki K., Nezu T., Takeuchi S., Takasawa R., Sunaga S., Yoshimori A., Ebizuka S., Abe T., Tanuma S. 2010. Structural insights into the hot spot amino acid residues of mushroom tyrosinase for the bindings of thujaplicins. Bioorg. Med. Chem. 18: 8112-8118. DOI: 10.1016/j.bmc.2010.08.056.

Trust T.J. 1975. Antibacterial activity of tropolone. Antimicrob. Agents Chemother. 7: 500-506. DOI: 10.1128/AAC.7.5.500.

Trust T.J., Bartlett K.H. 1975. Antibacterial activity of tropilidine and tropone. Antimicrob. Agents Chemother. 8: 381-383. DOI:10.1128/AAC.8.3.381.

Valero E., Garcia-Moreno M., Varón R., Garcia-Carmona F. 1991. Time-dependent inhibition of grape polyphenol oxidase by tropolone. J. Agric. Food Chem. 39: 1043-1046. DOI: 10.1021/jf00006a007.

Wakabayashi H., Yokoyama K., Hashiba K., Hashimoto K., Kikuchi H., Nishikawa H., Kurihara T., Satoh K., Shioda S., Muto S., Terakubo S., Nakashima H., Motohashi N., Sakagami H. 2003. Cytotoxic activity of tropolones against human oral tumor cell lines. Anticancer Res. 23: 4757-4763.

Wang M., Hashimoto M., Hashidoko Y. 2013a. Repression of tropolone production and induction of a Burkholderia plantarii pseudo-biofilm by carot-4-en-9, 10-diol, a cell-to-cell signaling disrupter produced by Trichoderma virens. PLOS ONE 8(11): e78024. DOI:10.1371/journal.pone.0078024.

Wang M., Hashimoto M., Hashidoko Y. 2013b. Carot4-en-9,10-diol, a conidiation-inducing sesquiterpene diol produced by Trichoderma virens PS1-7 upon exposure to chemical stress from highly active iron chelators. Appl. Environ. Microbiol. 79: 1906-1914. DOI:10.1128/AEM.03531-12.
Yamada J., Fujita K., Eto K., Sakai K. 2003. Cell growth and nutrient uptake by cell suspensions of Cupressus lusitanica. J. Wood Sci. 49: 5-10. DOI: 10.1007/s100860300001.

Yamaguchi T., Fujita K., Sakai K. 1999. Biological activity of extracts from Cupressus lusitanica cell culture. J. Wood Sci. 45: 170-173. DOI: 10.1007/BF01192336.

Yamasaki Y., Konno H., Noda K. 2008. Polyphenol oxidase from wheat bran is a serpin. Acta Biochim. Pol. 55: 325-328.

Yamato M., Ando J., Sakaki K., Hashigaki K., Wataya Y., Tsukagoshi S., Tashiro T., Tsuruo T. 1992. Synthesis and antitumor activity of tropolone derivatives. 7. Bistropolones containing connecting methylene chains. J. Med. Chem. 35: 2670-273. DOI: 10.1021/jm00080a010.

Yen T.-B., Chang H.-T., Hsieh C.-C., Chang S.-T. 2008. Antifungal properties of ethanolic extract and its active compounds from Calocedrus macrolepis var. formosana (Florin) heartwood. Bioresour. Technol. 99: 4871-4877. DOI: 10.1016/j.biortech.2007.09.037.

Yu J.Q., Komada H. 1999. Hinoki (Chamaecyparis obtusa) bark, a substrate with antipathogen properties that suppress some root diseases of tomato. Sci. Hortic. 81: 13-24. DOI: 10.1016/S0304-4238(98)00262-3.

Zhao J. 2007. Plant troponoids: Chemistry, biological activity, and biosynthesis. Curr. Med. Chem. 14: 2597-2621. DOI: 10.2174/092986707782023253.

Zhao J., Fujita K., Sakai K. 2005. Oxidative stress in plant cell culture: A role in production of $\beta$-thujaplicin by Cupressus lusitanica suspension culture. Biotechnol. Bioeng. 90: 621-631. DOI: 10.1002/bit.20465.

Zhao J., Fujita K., Yamada J., Sakai K. 2001. Improved ß-thujaplicin production in Cupressus lusitanica suspension cultures by fungal elicitor and methyl jasmonate. Appl. Microbiol. Biotechnol. 55: 301305. DOI: 10.1007/s002530000555.

Zhao J., Fujita K., Sakai K. 2007. Reactive oxygen species, nitric oxide, and their interactions play different roles in Cupressus lusitanica cell death and phytoalexin biosynthesis. New Phytol. 175: 215229. DOI: 10.1111/j.1469-8137.2007.02109.x.

Zhao J., Guo Y., Fujita K., Sakai K. 2003. Involvement of cAMP signaling in elicitor-induced phytoalexin accumulation in Cupressus lusitanica cell cultures. New Phytol. 161: 723-733. DOI: 10.1111/j.1469-8137.2004.00976.x. 
Zhao J., Matsunga Y., Fujita K., Sakai K. 2006. Signal transduction and metabolic flux of ß-thujaplicin and monoterpene biosynthesis in elicited Cupressus lusitanica cell cultures. Metab. Eng. 8: 14-29. DOI: 10.1016/j.ymben.2005.09.002.

Zhao J., Sakai K. 2003a. Multiple signaling pathways mediate fungal elicitor-induced $\beta$-thujaplicin biosynthesis in Cupressus lusitanica cell cultures. J. Exp. Bot. 54: 647-656. DOI: 10.1093/jxb/erg062.

Zhao J., Sakai K. 2003b. Peroxidases are involved in biosynthesis and biodegradation of $\beta$-thujaplicin in fungal elicitor-treated Cupressus lusitanica. New Phytol. 159: 719-731. DOI: 10.1046/j.14698137.2003.00841.x

Zhao X., Sugawara T., Kuroda S., Arisawa J., Kimura K. 2009. Antimicrobial activity of B-thujaplicin (hinokitiol) on heterotrophic bacteria isolated from reverse osmosis water using for the preparation of hemodialysis fluids. In: Dössel O. and Schlegel W.C. (Eds.), WC 2009, IFMBE Proceedings/25/VII, pp. 30-33.

Zhao J., Zheng S.-H., Fujita K, Sakai K. 2004. Jasmonate and ethylene signaling and their interaction are integral parts of the elicitor signaling pathway leading to $\beta$-thujaplicin biosynthesis in Cupressus lusitanica cell cultures. J. Exp. Bot. 55: 1003-1012. DOI: $10.1093 / \mathrm{jxb} / \mathrm{erh} 127$.

Zhu Y.J., Qiu L., Zhou J.J., Guo H.Y., Hu Y.H., Li Z.C., Wang Q., Chen Q.X., Liu B. 2010. Inhibitory effect of hinokitiol on tyrosinase activity and melanin biosynthesis and its antimicrobial activities. J. Enzyme Inhib. Med. Chem. 25: 798-803. DOI: $10.3109 / 14756360903476398$. 